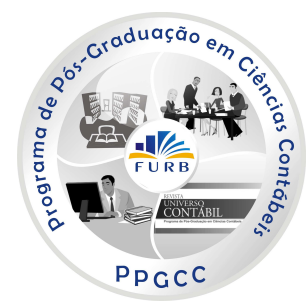

\title{
GERENCIAMENTO DA APRESENTAÇÃO: UMA ANÁLISE DA UTILIZAÇÃO DE GRÁFICOS NOS RELATÓRIOS DA ADMINISTRAÇÃO'
}

\author{
MANAGEMENT PRESENTATION: AN ANALYSIS OF THE USE OF VISUALS \\ RESOURCES IN THE BRAZILIAN CORPORATIONS' MANAGEMENT REPORTS
}

\section{PRESENTACIÓN DE GESTIÓN: UNA ANÁLISIS DEL USO DE RECURSOS VISUALES EN LOS INFORMES ADMINISTRATIVAS DE LAS EMPRESAS BRASILEÑAS}

\author{
Marina Dutra do Nascimento \\ Bacharel em Ciências Contábeis pela Universidade de Brasília \\ Endereço: QNG 23, Casa 23 \\ CEP: $72130-230$ - Brasília/DF - Brasil \\ E-mail: marinanascimento@terra.com.br \\ Telefone: (61) 9667-0732
}

Fernanda Fernandes Rodrigues

Mestre em Ciências Contábeis pela Universidade de Brasília Professora do Departamento de Contabilidade da Universidade de Brasília - UnB Endereço: Universidade de Brasília, Campus Universitário Darcy Ribeiro CEP: 70910-900 - Brasília/DF - Brasil E-mail: fernandes@unb.br Telefone : (61) 3372-9670

Pedro Henrique Melo Albuquerque Mestre em Estatística e Probabilidade pela UFMG Professor do Departamento de Administração da Universidade de Brasília -UnB Endereço: SQS 208 Bloco G, Apto. 202 CEP: 70910-900 - Brasília/DF - Brasil E-mail: pedroa@unb.br Telefone: (61) 3443-5186

\section{César Augusto Tibúrcio Silva \\ Doutor em Controladoria e Contabilidade pela Universidade de São Paulo Professor Departamento de Ciências Contábeis e Atuariais da Universidade de Brasília. Endereço: SQS 116 Bloco A, Apto. 402 CEP: 70382-010 - Brasília/DF -Brasil E-mail: cesaraugustotiburciosilva@gmail.com Telefone: (61) 3346-8261}

\footnotetext{
1 Artigo recebido em 20.09.2011. Revisado por pares em 06.12.2011. Reformulado em 13.04.2012. Recomendado para publicação em 15.04.2012 por Ilse Maria Beuren. Publicado em 31.03.2013. Organização responsável pelo periódico: FURB.
} 


\section{RESUMO}

O objetivo desse estudo é identificar o emprego de recursos visuais nos Relatórios de Administração das empresas brasileiras e analisar a influência dos gráficos na neutralidade das informações apresentadas. Foram analisados os relatórios de 203 empresas, dos mais diferentes setores, referentes ao período compreendido entre 1997 e 2009. Destes, buscou-se analisar a quantidade, tipos e características dos elementos visuais apresentados (gráficos, tabelas, fotos, etc.). A pesquisa evidenciou que, com o passar dos anos, a utilização desses recursos visuais foi aumentando, em geral. Entretanto, os tipos de gráficos exibidos não sofreram variações, sendo os que utilizam colunas em sua composição os mais empregados. $\mathrm{O}$ estudo mostrou também que uma parcela desses diagramas pode dar margem a uma interpretação indevida em consequência das técnicas empregadas em sua elaboração.

Palavras-chaves: Relatório da Administração. Gráficos. Evidenciação contábil. Gerenciamento da apresentação.

\section{ABSTRACT}

The study aims to identify the use of visuals resources at Brazilian corporations' Management Reports and to analyze the influence of graphs on the neutrality of submitted information. We analyzed 203 companies from different sectors, between 1997 and 2009. Of those, we sought to examine the quantity, types and characteristics of the visual elements (graphs, tables, photos, etc.). In general, the research showed that, over the years, the use of visual aids has increased. However, the types of graphs have not undergone variations, and the most used were the ones with columns in their composition. The study also showed that a portion of the diagrams can give rise to a misguided interpretation as a result of the techniques of its preparation.

Keywords: Management Report. Graphs. Accounting disclosure. Presentation Management.

\section{RESUMEN}

Este estudio tiene como objetivo identificar el uso de recursos visuales en los Informes Administrativas de las empresas brasileñas y analizar las influencias de los gráficos sobre la neutralidad de las informaciones presentadas. Doscientas y tres empresas se analizaron desde diferentes sectores, en el período comprendido entre 1997 y 2009. De ellos, hemos tratado de examinar la cantidad, tipos y características de los elementos visuales (gráficos, tablas, fotos, etc.) La búsqueda mostró que, a través de los años, el uso de estas ayudas visuales fue aumentado en general. Sin embargo, los tipos de gráficos mostrados no han sufrido variaciones, y aquellos que utilizan columnas en su composición son los más empleados. Este estudio demostró también que una porción de estos diagramas puede elevar una interpretación injustificada como resultada de las técnicas empleadas durante su preparación.

Palabras clave: Informe Administrativo. Gráficos. Contabilidad de la evidencia. Presentación de gestión.

\section{INTRODUÇÃO}

De acordo com a Lei das Sociedades por Ações nº 6.404, de 15 de dezembro de 1976, 
é obrigatória a publicação do Relatório da Administração (RA) juntamente com as Demonstrações Contábeis tradicionais do encerramento do exercício social (BRASIL, 1976). O conteúdo das informações retratadas nesse relatório deve girar em torno dos negócios sociais e principais fatos administrativos ocorridos no exercício (art. 133, inciso I). Dessa forma, dentre esse conjunto de informações divulgado pelas companhias abertas, destaca-se o Relatório da Administração por sua natureza descritiva e linguagem mais acessível, favorecendo o entendimento da situação econômico-financeiro das empresas a um maior número de usuários (SPRINGER, 1992; ROGERS; GRANT, 1997; YUTHAS; ROGERS; DILLARD, 2002, DALMÁCIO; PAULO, 2004; SILVA; RODRIGUES, 2010).

A CVM publicou no Parecer de Orientação nº 15, de dezembro de 1987 informações acerca do RA, sugerindo às companhias abertas a divulgação de informações relevantes no relatório, de maneira a aperfeiçoar o seu conteúdo frente aos usuários externos (CVM, 1987). É importante ressaltar que a CVM aconselha que essas sugestões não devam inibir a criatividade da administração na elaboração do mesmo. Entretanto é levantada a questão de que o RA pode não ser utilizado com a potencialidade total, servindo muitas vezes apenas para apresentar as demonstrações contábeis e expressar agradecimentos em geral, podendo gerar um cenário dissonante com a realidade da empresa ou do mercado em que a mesma atua.

Observa-se, na prática, que os RAs, apesar de serem relatórios narrativos, muitas vezes apresentam diversos tipos de recursos visuais, como gráficos e tabelas. Esses recursos são usados por acreditar que possam simplificar, ou mesmo sintetizar as informações, facilitando assim o entendimento. Segundo Clatworthy e Jones (2001), os relatórios contábeis narrativos são cada vez mais importantes, quando comparados aos relatórios financeiros externos. Essas mudanças reforçam uma evolução potencial do relatório anual, passando de um documento produzido estatutariamente a um documento em que prevalecem narrativas, fotografias e gráficos.

Monteiro (1999) descreve os gráficos como um instrumento utilizado pela sociedade com o propósito de ampliar sua capacidade de interpretar as informações quantitativas e estabelecer relações entre as mesmas. Para o autor, os gráficos estatísticos, que abordam diferentes temas, surgiram com o objetivo específico de otimizar o processo de comunicação, empregando o menor tempo possível para tornar uma informação compreendida. Ao longo da história, os gráficos foram inseridos em outros contextos com objetivos diversos, sendo largamente utilizados pelos meios de comunicação de massa, com a finalidade de enfatizar determinados aspectos da informação.

Portanto, verifica-se que os usuários que lidam com informação podem estar sujeitos a interpretações distorcidas inferidas de gráficos não adequados. As próprias organizações podem estar sujeitas a comunicar resultados de análises deturpados, devido à maior preocupação com a estética do que com a informação que os diagramas trazem. Outra possibilidade está no fato de que a administração possa querer controlar e manipular a impressão transmitida aos usuários (gerenciamento de impressão).

Segundo Beattie e Jones (2002a), o gerenciamento da impressão (impression management), considerado como uma extensão da literatura sobre gerenciamento de resultados (earnings management), ocorre por meio da manipulação das informações apresentadas nos relatórios, com o objetivo de gerar uma impressão equivocada da real situação econômico-financeira da empresa, porém, associado a um contexto mais amplo, da análise documental do relatório anual e, em particular, por meio de métodos de divulgação, como gráficos e ilustrações (SYDSERFF; WEETMAN, 2002). Esse gerenciamento, de acordo com esses autores, pode ocorrer tanto por meio da manipulação do conteúdo e da sintaxe das narrativas contábeis ou pela manipulação no formato de apresentação de gráficos ou imagens. 
Nesse sentido, os administradores podem utilizar o RA para atender aos seus próprios interesses, conforme apresentado por Iudícibus (2009), ao afirmar que os relatórios são normalmente enviesados pelo otimismo inconsequente. Tessarolo, Pagliarussi e Luz (2010), analisaram os relatórios de 49 empresas brasileiras de 2002 e 2003 e também corrobora essa hipótese, ao verificar que esses são enviesados pelo "escritor", sendo que eles levam os créditos pelas boas notícias e evitam a culpa das más notícias.

Conforme analisado por Beattie e Jones (1992), os gráficos também podem ser apresentados de maneira a distorcer as informações, com o objetivo de deturpar a interpretação do leitor. Os autores apresentam três maneiras diferentes de se gerenciar essas informações: (1) pelo viés da seletividade; (2) índice de lie factor; e (3) o realce de apresentação no desenho gráfico. $\mathrm{O}$ realce de apresentação costuma ser realizado ao se utilizar gráficos com a escala vertical não baseada em zero ou com o emprego da perspectiva em 3 dimensões (gráficos 3-D).

Assim, o objetivo desse estudo é analisar os recursos visuais apresentados nos RA. Foi, portanto, formulada a seguinte questão de pesquisa: Quais mudanças significativas foram verificadas nos recursos gráficos utilizados nos relatórios da administração ao longo dos anos? A amostra da pesquisa foi composta por 203 empresas, onde se buscou analisar a quantidade, os tipos e características desses elementos visuais, bem como se há indicadores de realce de apresentação nos gráficos apresentados nesses relatórios.

A estrutura deste artigo divide-se em cinco sessões, sendo a parte inicial constituída pela introdução. Em sequência é apresentado o referencial teórico, discutindo-se a evidenciação contábil, a utilização de recursos visuais e elencados os estudos semelhantes a esse. Os procedimentos metodológicos são descritos na terceira sessão. A quarta sessão corresponde ao desenvolvimento da pesquisa em si com a demonstração das análises e interpretações dos dados. Finalmente, na quinta sessão são apresentadas as conclusões do estudo, bem como sugestões para pesquisas futuras.

\section{REFERENCIAL TEÓRICO}

\subsection{Utilização de Recursos Visuais}

Bedford e Beladouni (1962) afirmam que a "contabilidade é uma função do processo de comunicação". Isso ocorre, pois: há um emissor, que recebe a informação sobre um evento econômico da empresa, interpreta (decodifica) e seleciona a informação a ser comunicada. Então ele codifica a informação como uma mensagem que será enviada ao receptor, que também precisa conhecer essa linguagem para fazer a decodificação.

Nesse sentido, segundo Bedford e Beladouni (1962), se a mensagem é produzida com $100 \%$ de fidelidade e interpretada pelo receptor com $100 \%$ de fidelidade, pode-se dizer que há uma perfeita comunicação da mensagem. Dessa forma, de acordo com os autores, esse processo de comunicação contábil, pode sofrer prejuízos na fase de produção, pois o contador pode não conseguir interpretar e codificar os fenômenos econômicos (poderá haver ruídos (noise) na qualidade da mensagem contábil.

Assim, uma maneira de tentar melhorar esse processo de comunicação contábil, proposta por Pretto e Nakagawa (2000, apud ILUF, 2000), seria por meio da utilização de gráficos, quadros, esquemas, e outros, que permitiria uma melhor interação entre a contabilidade e os seus usuários. Portanto, as representações gráficas são utilizadas principalmente para facilitar a visualização de dados, aprimorando o processo de tomada de decisão. Lopes (1999) enfatiza que, ao ser elaborado um gráfico, existe uma parcela de perda de informação, pois as observações originais não são evidenciadas. Porém, frequentemente essa perda é pífia, se comparada com a concisão e facilidade de interpretação.

Para Reis (2008, p. 26), os gráficos: 
[...] libertam o espírito da tarefa de memorização e tornam-no disponível para a reflexão. A representação gráfica é talvez o modo mais simples de descrever a realidade nos seus aspectos mensuráveis: é um "desenho" representando um conjunto de quantidades referentes a determinados aspectos da realidade. O gráfico é um instrumento de síntese que permite utilizar o poder da visão para nos apercebermos imediatamente da forma geral sem, no entanto, deixar de evidenciar alguns aspectos particulares.

Cunha (1982) classifica os gráficos em dois tipos: gráficos de apresentação e gráficos de análise. Nessa pesquisa o foco serão os gráficos de apresentação, pois as representações de análise são voltadas para os profissionais de Estatística. Os demonstrativos de apresentação são usados para apresentar os fatos ao grande público, ao leigo em Estatística. Entre os tipos de gráficos de apresentação mais usados são destacados o gráfico linear ou cartesiano, gráfico em colunas, gráfico em setores, mais conhecido como gráfico "pizza”, o gráfico em barras e o gráfico em áreas.

A escolha do tipo de gráfico a ser utilizado, segundo Wurman (1991), é definida a partir do próprio conjunto de dados que devem ser diagramados. A opção deveria ser por aquela em que esse conjunto fique visualmente mais claro do que em qualquer outro tipo de visualização. Assim, os gráficos de linha são eficientes para demonstração da evolução ao longo do tempo e os gráficos de coluna são geralmente utilizados para a comparação de quantidade. Já os gráficos circulares, ou "pizza", devem ser utilizados apenas para comparar volumes substanciais, pois dividir gráficos circulares em muitas fatias pode impossibilitar a comparabilidade. Os gráficos de barra são utilizados para comparar categorias, sendo elas organizadas verticalmente, enquanto os valores possuem disposição horizontal. Esse tipo é usado para enfatizar a comparação de valores e dar menos ênfase ao tempo. Diferente dos gráficos de área, que se assemelham ao gráfico de linhas, porém com a área da linha até a base preenchida, esse tipo é utilizado para enfatizar a relação dos valores com o todo, isto é, sua magnitude ao longo do tempo.

Deste modo, para cada tipo de informação existiria um gráfico mais adequado. Atualmente, com a necessidade constante do maior número de informações no menor tempo possível, a utilização de gráficos, tabelas ou qualquer outra ferramenta que permita organizar dados e torná-los acessíveis a quem possa interessar, está sendo cada vez mais valorizada.

De acordo com Tufte (2001), as informações apresentadas nos gráficos devem ser claras, consistentes e precisas. Para que sejam inferidas as conclusões adequadas, o autor ainda preza por pouco espaço e muitos dados, ajudando o leitor a estabelecer relações e perceber diferenças, mesmo que sutis. O autor é considerado um pioneiro na análise de erros conceituais, muitas vezes graves, contidos em gráficos publicados em jornais e revistas de prestígio, em prol da estética.

Mattos (2011, p. 171) utiliza como exemplo tanto os relatórios corporativos como os relatórios governamentais:

[...] sempre cheios de números e gráficos, que não por acaso são de grande interesse para o próprio produtor da informação. Certamente estes relatórios se encaixam na categoria em que o produtor da informação tem grande interesse nos resultados. Só isso já é o suficiente para atribuirmos uma boa dose de desconfiança aos seus números e gráficos, possíveis portadores de distorções e apresentações tendenciosas. Especialmente se a empresa em questão não tem bons números para mostrar, e está ávida para passar uma boa imagem, ou o governo quer justificar um aumento de impostos ou exagerar os progressos realizados.

Ainda em relação aos gráficos nos relatórios anuais, Beattie e Jones (1992) identificaram três formas de riscos associadas. A primeira é relacionada à seletividade, isto é, os gráficos só apresentam determinadas variáveis em circunstâncias específicas, existindo a 
intenção de produzir um efeito positivo em seus usuários. Miranda et al. (2008), por exemplo, confirmou a apresentação do viés da seletividade em empresas brasileiras, quanto à escolha das variáveis apresentadas graficamente, comparando organizações com desempenho favorável e aquelas com resultado abaixo do esperado. Cho, Michelon e Patten (2011) encontraram este viés em relatórios de sustentabilidade.

Outra distorção é referente ao "Índice de lie factor", descrito pela primeira vez por Tufte, em 1983, em que o valor para descrever a relação entre o tamanho do efeito mostrado no gráfico e o tamanho do efeito nos dados deve ser diretamente proporcional. Isto é, ao dividir a representação dos números como fisicamente demonstrados na superfície do gráfico e suas respectivas quantidades representadas deve-se obter um valor entre 0,95 e 1,05. Beattie e Jones (2002a) utilizaram esse índice de discrepância como evidência experimental para verificar o nível de mensuração da distorção na percepção dos usuários.

Finalmente, a terceira forma de infidelidade gráfica, descrita por Beattie e Jones (1992), é o realce de apresentação no desenho gráfico. Um apelo quase sempre desnecessário e que não preza pela precisão e coerência da representação visual dos dados. Um exemplo desse realce de apresentação é descrito por Huff (1954), definindo-o como uma das principais armadilhas na representação de variáveis nos gráficos: a utilização de bases diferentes de zero. Não existe mudança nos números apresentados, a variação é somente na impressão causada. Nas ilustrações apresentadas nota-se o uso dos mesmos valores, porém cada gráfico induz a uma interpretação distinta.

Figura 1 - Variações do Gráfico

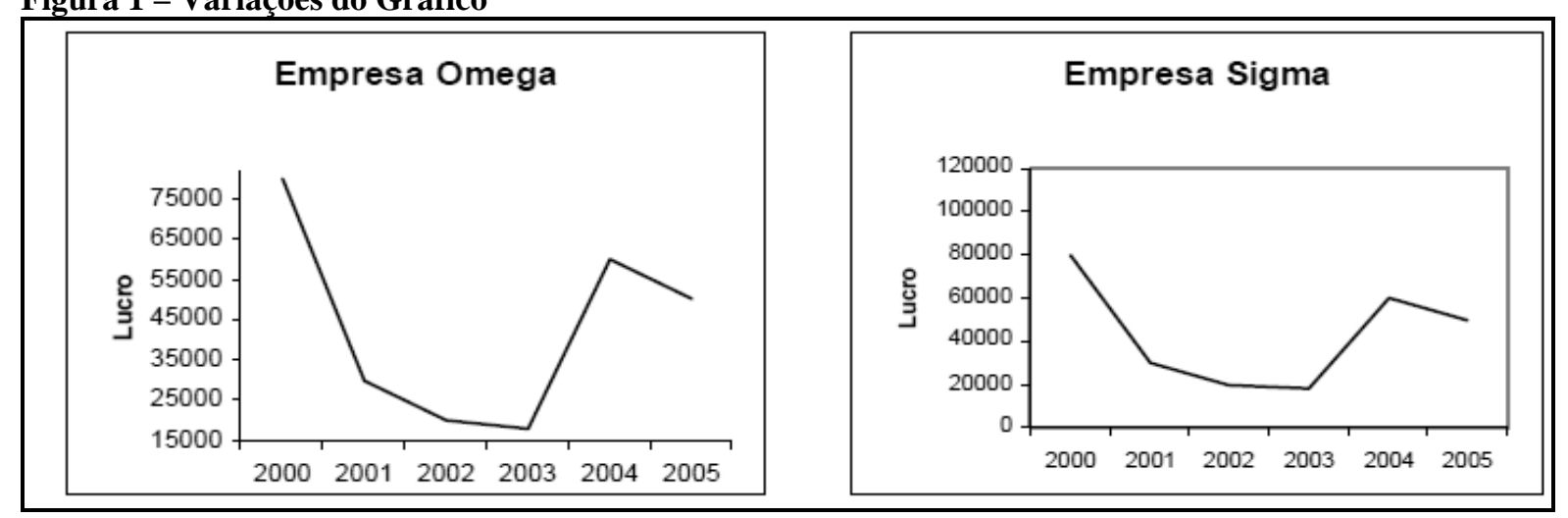

Fonte: Lima, (2007 p. 100)

Este efeito de distorção pode alterar consideravelmente a percepção dos usuários, como comprovado por Lima (2007), que ao apresentar os dois gráficos (Figura 1) questionou aos seus entrevistados qual das empresas apresenta o menor risco. Os resultados mostraram que a empresa que apresentou o gráfico não considerando a origem zero (gráfico à esquerda) apresentava, segundo os entrevistados, maior risco ao investimento. Entretanto, os dois gráficos são idênticos.

Outra maneira de deturpar as informações apresentadas nos gráficos é por meio da utilização da perspectiva em 3 dimensões (ou gráficos em 3-D). Mattos (2011) descreve que a utilização de uma dimensão sem valor numérico além de desnecessária pode tornar confusa a percepção da profundidade, modificando a interpretação da informação. Ao se deparar com um diagrama que utiliza esse estilo, é sabido que a profundidade não está representando nenhuma informação, mas a tendência é de interpretar essa profundidade ou compará-la com as outras medidas.

Wurman (1991) explicita que, mesmo existindo gráficos que realmente distorcem os dados essenciais, tornando difícil para o usuário inferir a realidade, não quer dizer que eles são um meio de comunicação menos válido do que as palavras. $\mathrm{O}$ autor afirma que qualquer 
ferramenta utilizada para transmitir informações pode ser usada para iludir. Entretanto, para evitar esse aspecto vulnerável dos diagramas, eles devem ser usados como simples mapas, cujo fim específico é facilitar o processamento de informações pelos usuários. Os gráficos devem auxiliar no processo decisório (WURMAN, 1991).

\subsection{Estudos Realizados com o Relatório da Administração}

Reconhecendo a relevância dos RAs como complemento das demonstrações financeiras publicadas, alguns estudos podem ser destacados. Um dos temas mais recorrentes é relacionado aos aspectos linguísticos. Dias Filho (2000) destaca a utilização de termos técnicos utilizados na Contabilidade, inviabilizando o entendimento do usuário médio das informações. $\mathrm{O}$ autor verificou, na maioria dos casos analisados, que o usuário não conseguia compreender as informações publicadas nos relatórios, simplesmente por desconhecer a definição dos termos. Assim, as informações contábeis podem induzir a má interpretação ou subutilização, deixando de cumprir a finalidade a que se propõem.

Clatworthy e Jones (2001), em sua pesquisa a respeito da variação de legibilidade, encontraram evidências a respeito de a declaração do presidente ser a seção do RA de maior facilidade de leitura. Porém, não confirmaram o uso dessa variação com informações que enfatizam o desenvolvimento ou a regressão da companhia.

Na pesquisa realizada por Yuthas, Rogers e Dillard (2002), a partir dos princípios de Habermas (compreensibilidade, confiabilidade, sinceridade e legitimidade), os autores identificaram um menor nível de informações ligadas a fatores internos e maiores índices de distorção nas empresas com desempenho abaixo do esperado.

A respeito dos aspectos sócio-ambientais e indicadores econômico-financeiros, Dalmácio e Paulo (2004) levantaram os dados publicados em 2003 de empresas industriais do Estado do Espírito Santo e concluíram que o Relatório de Administração é o instrumento que permite, de maneira mais flexível, a evidenciação de informações sociais e os índices econômico-financeiros, maximizando as informações geradas pela empresa e atendendo aos interesses dos usuários externos.

Li (2006) verificou a existência de maior dificuldade de leitura nos relatórios das empresas que apresentaram desempenho inferior, o que pode indicar a preocupação dos gestores em ocultar informações negativas dos investidores. Em outra abordagem, relacionando o desempenho financeiro das entidades com o conteúdo de seu relatório anual, Silva e Rodrigues (2006) confirmaram a existência de viés na divulgação dos dados referentes ao desempenho, o que também pode prejudicar a análise dos usuários.

Vicente et al. (2007) procuraram verificar a aderência do relatório da administração das empresas listadas no novo mercado da Bolsa de Valores de São Paulo (BOVESPA) às diretrizes emanadas pela Conferência das Nações Unidas para Comércio e Desenvolvimento (UNCTAD) destacando que os relatórios ainda não apresentam total adesão às normas devido ao retrato superficial de itens estratégicos.

A respeito da normatização, Gallon e Beuren (2008) compararam a evidenciação de itens obrigatórios pela Lei $n^{\circ}$ 6.404/76 e recomendados pela Comissão de Valores Mobiliários por meio do Parecer de Orientação $n^{\circ} 15 / 87$ com os itens de divulgação espontânea e concluíram que a transparência e a qualidade dos relatórios é restrita às exigências legais, devido às empresas brasileiras apresentarem níveis baixos de evidenciação voluntária.

Cunha e Silva (2009) utilizaram o enfoque de gerenciamento de impressões nas narrativas contábeis de empresas brasileiras, mediante a análise da facilidade de leitura, isto é, se as empresas utilizam textos mais ou menos complexos para dissimularem informações sobre seu desempenho. Os autores analisaram notas explicativas e relatórios da administração de empresas listadas na Bovespa durante o período de 2003 a 2007, encontrando relação entre o porte da empresa, o crescimento contínuo e a facilidade de leitura de seus textos. 
Recentemente, Silva e Rodrigues (2010) testaram a relevância do Relatório de Administração para a avaliação do desempenho das empresas a partir do método experimental. Os autores concluíram que o RA apesar de influenciar na percepção dos participantes do estudo quanto aos níveis de endividamento e competitividade, não existe o mesmo impacto com a tomada de decisão. Para os autores, o relatório só executará plenamente sua função no processo informativo quando obedecer "fielmente às recomendações dos órgãos competentes e não oferecer informações distorcidas ou insuficientes".

\subsection{Estudos Realizados na Contabilidade com Enfoque nos Recursos Visuais}

Pioneiramente, Beattie e Jones (1992) realizaram uma investigação em 240 relatórios de administração no Reino Unido referentes ao ano de 1989, procurando detalhar a natureza, a extensão e as conformidades nas quais os gráficos eram apresentados. Os resultados apresentaram a média de utilização de 5,9 gráficos por relatório e destacaram o preocupante fato de não existir regras específicas para esse tipo de informação complementar. Com isso, foi sugerida uma auditoria voltada para realizar observações a respeito dos dados ali exibidos. Além disso, os autores também ressaltaram a incidência maior de utilização de recursos visuais para enfatizar resultados favoráveis nas organizações.

Mesmo comprovada a influência desses "apelos visuais", os estudos nacionais a respeito da utilização de gráficos e tabelas nas demonstrações e relatórios contábeis são poucos. Pereira, Fragoso e Ribeiro Filho (2004) estabeleceram um comparativo do nível de percepção das representações gráficas dos usuários de informações contábeis nas cidades de Florianópolis (SC) e Recife (PE), destacando que estes são muito valorizados devido ao fato de melhorarem a compreensão das informações contábeis.

$\mathrm{Na}$ avaliação de Lima (2007), tendo como base questionários respondidos por 1.850 discentes dos cursos de Administração e Ciências Contábeis, foi constatado que a apresentação de gráficos nos relatórios anuais pode alterar a percepção dos usuários e influenciar no processo decisório. Um dos métodos descritos é a utilização de gráficos com base zero, onde, segundo o autor, o efeito da dispersão dos dados visualmente parece menor podendo amenizar a apresentação dos riscos da entidade.

No estudo de Miranda et al. (2008), os autores realizaram uma pesquisa exploratória em 37 Relatórios da Administração de empresas de capital aberto referentes aos anos de 2000 a 2006. Os autores corroboram com os resultados de Beattie e Jones (1992) de que as empresas em situação desfavorável apresentaram menor quantidade de elementos gráficos. Entretanto, a empresa que apresenta gráficos destacando pontos negativos utiliza uma área maior na intenção de evidenciar os pontos fortes da entidade. Também foi observada a diferenciação das variáveis nos gráficos, contrapondo as empresas com resultados financeiros positivos àquelas que apresentaram prejuízo no período analisado.

Jones (2011) estudou os relatórios sociais e ambientais. O autor encontrou uma clara evidência de gerenciamento de impressão com o uso de gráficos. As empresas destacam nos gráficos as boas notícias mais que as más notícias. Além disto, empresas com grande impacto nos setores de atuação tendem a apresentar mais notícias favoráveis; isto acontece, em especial, em empresas com elevado impacto, com extrativas.

Como se pode observar, existem diversas pesquisas nacionais e internacionais realizadas, utilizando-se do relatório da administração como objeto de estudo. Porém, poucas pesquisas nacionais focaram nos recursos gráficos apresentados nesses relatórios. O diferencial dessa pesquisa encontra-se no fato de analisar as características dos recursos visuais apresentados nos relatórios da administração publicados pelas empresas brasileiras em uma série histórica de doze anos. 


\section{PROCEDER METODOLÓGICO}

O universo desse estudo é composto por 752 empresas de capital aberto, com cadastro ativo, listadas na CVM em março de 2011. Desse total de empresas, verifica-se que existem 268 empresas que tiveram seus pedidos de abertura de capital concedidos pela CVM até 1997. Destas, foram excluídas aquelas que não apresentaram todos os relatórios referentes aos 13 anos analisados. Com isso, o estudo se baseia em uma amostra constituída por 203 organizações de 25 setores da economia. Reconhece-se que essa é uma limitação do estudo, na medida em que existe o "viés da sobrevivência". Porém, isso não gera prejuízos, por serem análises do tipo "time series", independentes das empresas analisadas possuírem desempenho superior à média de mercado.

A fonte de obtenção dos dados foi o site da Comissão de Valores Mobiliários. Todos os registros foram coletados por meio da consulta às demonstrações financeiras padronizadas, totalizando 2.639 Relatórios Anuais Corporativos referentes à competência de 1997 a 2009.

Desses relatórios efetuou-se a análise das características dos recursos visuais apresentados, primeiramente definindo a natureza do elemento, enumerando a quantidade de gráficos, tabelas, ilustrações e fotos. Das 101 empresas que apresentaram gráficos em seus relatórios, efetuou-se a análise das características desses gráficos, classificando-os a partir do formato apresentado como: gráficos de linha, coluna, barras, "pizza" e de área. Finalmente, analisou-se se haviam realce da apresentação nos gráficos apresentados nesses relatórios: a quantidade de gráficos com a escala vertical não baseada em zero e o emprego da perspectiva em 3 dimensões.

\section{RESULTADOS, ANÁLISES E DISCUSSÃO}

Considerando a metodologia de pesquisa apresentada, constatou-se que, a partir da amostra contendo 203 empresas, 67 não apresentaram qualquer tipo de elemento visual em seus relatórios. Porém, das 136 empresas restantes, 35 não apresentaram gráficos, especificamente. As 101 empresas que apresentaram gráficos totalizaram aproximadamente $50 \%$ de toda amostra. Entretanto, o estudo permitiu a constatação de que os diagramas não foram os recursos mais utilizados, representando apenas $45,30 \%$ de todos os recursos visuais, contra a parcela de $51,48 \%$ que as tabelas representam. Os anos em que a utilização de gráficos superou a de tabelas foram: 2004, 2005, 2006, 2007 e 2009. Porém as diferenças observadas entre o número de gráficos e o de tabelas nesses anos variaram de $0,6 \%$ em 2004 a $8,65 \%$ em 2005. Considerando todo o espaço de tempo estudado, a maior diferença é observada no ano 2000, pois os relatórios apresentaram 281 tabelas, contra 131 gráficos. Essa variação representa uma diferença de $44,92 \%$ do total de elementos visuais desse ano. A Eletrobrás foi a empresa que apresentou a maior quantidade de tabelas tanto durante todo o período, totalizando 275, quanto em um único relatório, exibindo 51 tabelas em 2008.

Quanto às ilustrações, o total de 307 observações representou apenas 3,04\% do total de 9.110 elementos gráficos utilizados. Os principais exemplos de figuras apresentadas pelas entidades foram: organogramas em geral, principalmente acerca das divisões departamentais, mapas que representam a atuação geográfica e também foram considerados os desenhos que representam os selos de prêmios e reconhecimentos apresentados. Por isso, a empresa que totalizou o maior número de ilustrações foi a Celulose Irani S.A., uma empresa do ramo de celulose e derivados que apresentou nos relatórios referentes aos anos de 2007, 2008 e 2009 seus selos de reconhecimento dos projetos sociais, ambientais, de mercado e recursos humanos, totalizando 37 selos. Alguns exemplos são: o "Anuário Valor 1000", realizado pela Revista Valor Econômico, "Selo Anpei de Empresa Inovadora", concedido pela Associação Nacional de Pesquisa e Desenvolvimento das Empresas Inovadoras e "As Melhores da Dinheiro", prêmio concedido pela Revista Isto É Dinheiro.

Nessa amostra, apenas 3 empresas apresentaram fotos. A Braskem S.A. publicou uma 
foto em 2002, apresentando a abertura de seus negócios na Bolsa de Nova York e uma foto em 2003 de seu showroom do Centro de Inovação e Tecnologia. Além dessa, a Ferrovia Centro Atlântica S.A. e a Fras-Le S.A. apresentaram 8 fotos cada. Entretanto, enquanto a primeira publicou suas fotos divididas nos anos de 2007 a 2009, a Fras-le disponibilizou todas em seu relatório de 2008.

Como demonstrado na Tabela 1, a utilização de recursos visuais foi crescente ao longo dos anos. Enquanto o total apresentado em 1997 equivale a apenas 3\% do montante total de 9.110 elementos, a soma de gráficos, tabelas, ilustrações e fotos em 2009 representa 14,06\% desse total.

Tabela 1 - Elementos Gráficos Utilizados

\begin{tabular}{c|c|c|c|c|c}
\hline ANO & GRÁFICOS & TABELAS & ILUSTRAÇÕES & FOTOS & TOTAL \\
\hline 1997 & 87 & 186 & 0 & 0 & 273 \\
1998 & 70 & 185 & 1 & 0 & 256 \\
1999 & 126 & 243 & 3 & 0 & 372 \\
2000 & 131 & 281 & 2 & 0 & 414 \\
2001 & 178 & 288 & 8 & 0 & 474 \\
2002 & 224 & 318 & 14 & 1 & 557 \\
2003 & 288 & 375 & 14 & 1 & 678 \\
2004 & 412 & 407 & 20 & 0 & 839 \\
2005 & 462 & 387 & 18 & 0 & 867 \\
2006 & 462 & 436 & 36 & 2 & 934 \\
2007 & 544 & 472 & 50 & 10 & 1068 \\
2008 & 504 & 527 & 56 & 4 & 1097 \\
2009 & 639 & 585 & 53 & 18 & 1281 \\
\hline TOTAL & 4.127 & 4.690 & 275 & & 9.110 \\
\hline
\end{tabular}

Fonte: Elaboração Própria

Investigou-se, ainda, se o número de páginas do relatório poderia influenciar no crescimento do número de gráficos apresentados. Por isso analisou-se se havia relação entre essas duas variáveis. Os resultados obtidos indicam que, para 71 empresas da amostra, houve correlação significativa, isto é, com nível de significância das correlações inferior a 5\% $(\mathrm{p}<0,05)$ - considerando aqui a amostra com 101 empresas que apresentam gráficos, o que demonstra uma proporção de aproximadamente $70 \%$ do total. Esses valores revelam a existência de simetria entre o crescimento físico dos relatórios (aumento do volume de páginas) e a presença de diagramas nos RAs.

É importante destacar que apenas a empresa Cecrisa Revestimentos Cerâmicos S.A. apresentou correlação significativa negativa, justificado pelo fato de que, apesar do número de páginas de seus relatórios ter sofrido uma queda no período analisado, variando entre 08 páginas em 1997 e 04 páginas em 2009, o número de gráficos aumentou, diferindo da tendência de crescimento conjunto analisada.

\subsection{Quantidade de Gráficos}

Ao longo do período analisado foi constatada uma variação relevante do número de gráficos utilizados. Apesar de nos anos de 1998 e 2008 existirem quedas, o aumento foi substancial, como pode ser observado no Gráfico 1.

A estatística descritiva da análise da quantidade de gráficos verificou que o número máximo de gráficos exibidos em um único relatório variou de 12, da Vale S.A. em 1998 até 75 em 2009, apresentados pela Vulcabras S.A. Entretanto, as empresas que apresentaram a maior quantidade total de gráficos são: a Braskem S.A. com 157, a Vulcabras S.A com 148 e a Cemig com 129 diagramas. O total geral foi de 4.127 gráficos, representando uma média de 
1,56 gráficos por relatório anual corporativo.

Gráfico 1 - Quantidade de Gráficos Utilizados

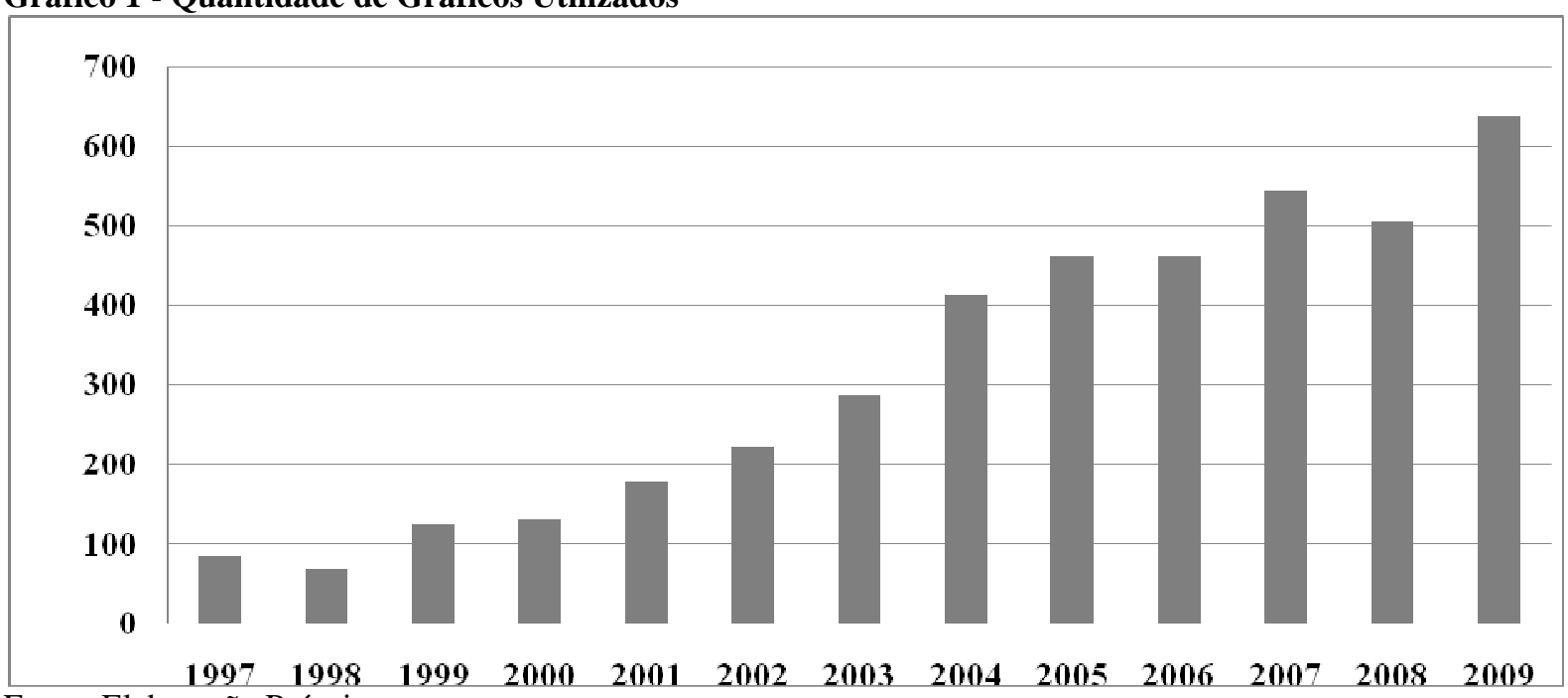

Fonte: Elaboração Própria

Embora a Vulcabras S.A. não seja a empresa com o maior número de gráficos totais apresentados, ela foi a principal responsável pelo aumento substancial ocorrido em 2009. Enquanto o desvio-padrão do número de gráficos utilizados em 2008 era 3,35, com o aumento de 135 gráficos em 2009, o desvio-padrão passou a ser 4,23. Importante ressaltar, que o número de gráficos apresentados pela Vulcabras em 2009 representa 55,56\% desse aumento.

\subsection{Tipos de Gráficos}

A segunda questão apresentada refere-se aos tipos de gráficos apresentados. Após a classificação nas 5 formas básicas: linha, colunas, barras, setores e área, verificou-se que não houve variação dos tipos utilizados ao longo do período analisado. Como mostra a Tabela 2, em todos os anos os gráficos mais utilizados foram o de colunas, seguidos pelos de setores, os cartesianos, os de barra e por fim, os gráficos que utilizam áreas para aferir resultados. A única variação foi em 1998, pois os gráficos de área superaram os com barras.

Tabela 2 - Tipos de Gráficos Utilizados

\begin{tabular}{|c|c|c|c|c|c|c|}
\hline ANO & LINHAS & COLUNAS & PIZZA & BARRAS & ÁREA & TOTAL \\
\hline 1997 & 1 & 56 & 30 & 0 & 0 & 87 \\
\hline 1998 & 2 & 46 & 18 & 1 & 3 & 70 \\
\hline 1999 & 10 & 71 & 42 & 2 & 1 & 126 \\
\hline 2000 & 28 & 73 & 30 & 0 & 0 & 131 \\
\hline 2001 & 28 & 99 & 51 & 0 & 0 & 178 \\
\hline 2002 & 28 & 142 & 53 & 1 & 0 & 224 \\
\hline 2003 & 40 & 180 & 56 & 12 & 0 & 288 \\
\hline 2004 & 50 & 278 & 81 & 2 & 1 & 412 \\
\hline 2005 & 40 & 327 & 88 & 6 & 1 & 462 \\
\hline 2006 & 44 & 300 & 115 & 2 & 1 & 462 \\
\hline 2007 & 51 & 364 & 122 & 4 & 3 & 544 \\
\hline 2008 & 32 & 345 & 123 & 3 & 1 & 504 \\
\hline 2009 & 47 & 445 & 138 & 8 & 1 & 639 \\
\hline TOTAL & 401 & 2.726 & 947 & 41 & 12 & 4.127 \\
\hline
\end{tabular}

Fonte: Elaboração Própria 
Os gráficos cartesianos representaram 9,72\% do total e estavam inseridos nos relatórios de 58 empresas. Dentre as que apresentaram o maior número de gráficos de linha estão: a Confab Industrial S.A., a Sabesp - Cia Saneamento Básico Estado São Paulo e a Vale S.A. com 53, 32 e 29 gráficos respectivamente. A maior taxa auferida foi de 9 gráficos em um relatório, que pertence a Confab no período de 2001 a 2004. Ainda se destaca a Drogasil S.A. por ter sido a segunda organização que mais utilizou gráficos cartesianos em um relatório, apresentando 8 no RA de 2009. Esses gráficos foram utilizados principalmente para demonstrar a evolução de resultados, como margem líquida e EBITDA, mas também exibiram a produção das entidades ao longo do tempo. Também foram considerados lineares os gráficos que representam as flutuações dos preços de ações, como o Gráfico 2, que reflete a instabilidade do mercado de capitais mundial decorrente da crise pela qual o sistema financeiro passou em 2008, exibido pelo Banco do Brasil S.A.

\section{Gráfico 2 - Gráfico Linear de Ações}

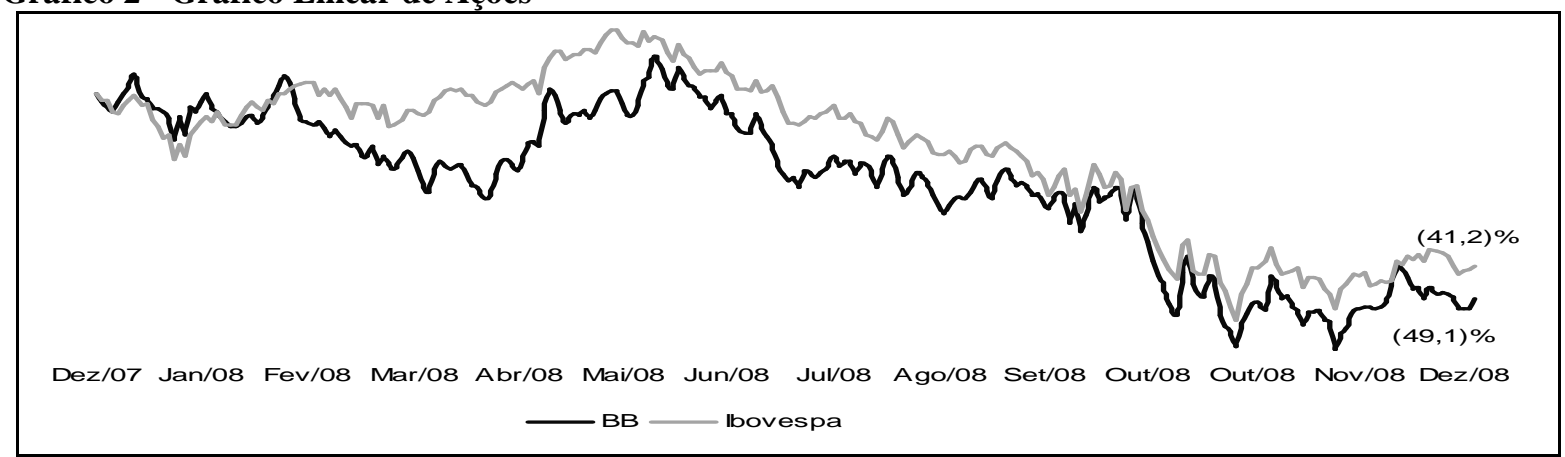

Fonte: Relatório Anual Corporativo - Banco do Brasil S.A. (2008, p. 7)

A utilização de gráficos que utilizam colunas em sua composição variou de 55,62\% em 2001 até 70,78\% em 2005. O total representa 66,05\% de toda amostra de gráficos analisados. A média alcançada foi 13,43 gráficos de coluna por empresa. Somente 5 empresas não utilizaram desse formato em seus relatórios, são elas: Bardella S.A., Cia Estadual de Geração e Transmissão de Energia Elétrica, Dohler S.A., Marisol S.A., e Petropar S.A. Por outro lado, as duas empresas que apresentaram o maior número desse tipo específico igualamse àquelas com o maior número de gráficos totais. A Braskem S.A. utilizou de 128 gráficos em seus relatórios e a Vulcabras S.A., 123. O maior índice de utilização em apenas um relatório pertence também a Vulcabras, com 69 gráficos de coluna em 2009. O ano que alcançou a maior quantidade de gráficos de coluna foi 2009 com 16,32\% do total, contra 1998 que representou apenas $1,69 \%$ dos 2.726 . Uma variação desse tipo de gráfico é o de colunas justapostas, o qual representa a relação entre categorias. Um exemplo é o Gráfico 3, constante no RA de 2002 da Braskem, que representa a proporção da moeda nacional e estrangeira na evolução do endividamento de curto prazo da entidade.

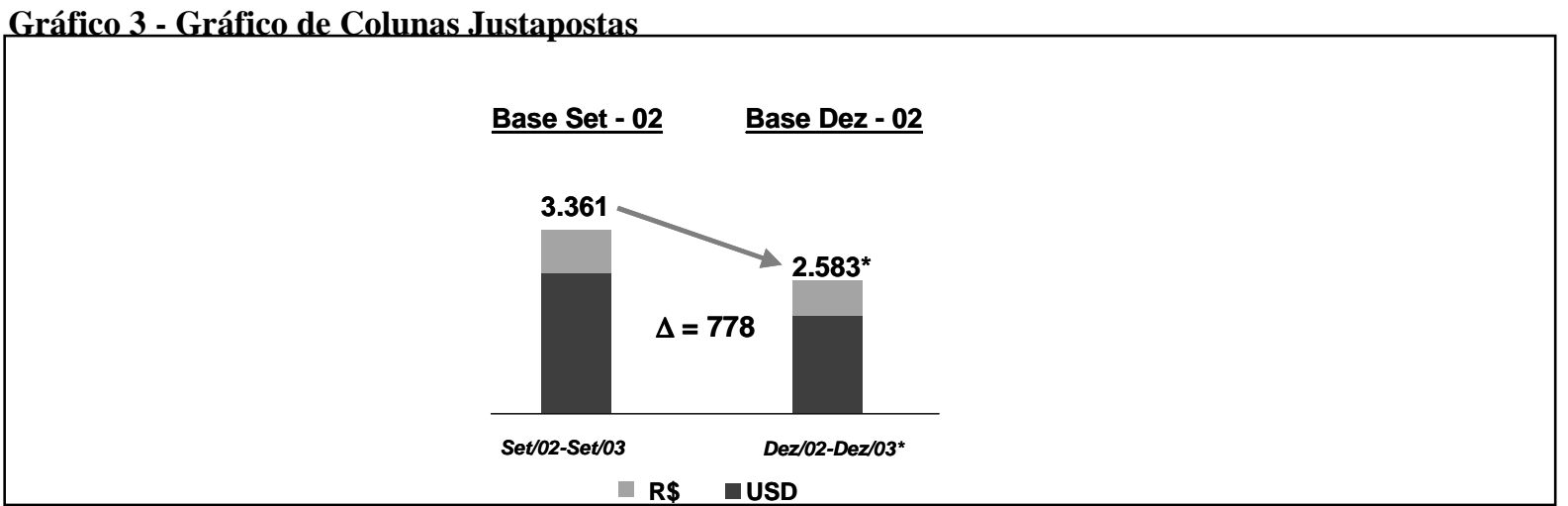

Fonte: Relatório Anual Corporativo - Braskem S.A. (2002, p. 20) 
Os gráficos em que cada categoria corresponde a um setor de um círculo, isto é, os gráficos de "pizza", representaram 22,95\% de toda a amostra. A Randon S.A. Implementos e Participações apresentou 21 gráficos desse formato em 2008, representando 23,86\% do total de 88 gráficos de "pizza" exibidos pela empresa. Essa empresa é seguida pela Companhia de Gás de São Paulo - Comgás, que somou 49 desses gráficos em todo o período analisado. Importante ressaltar que gráficos conhecidos como "rosca" também foram incluídos nessa categoria, por utilizar setores de um círculo para demonstrar o relacionamento com o todo. A Fras-Le S.A. utilizou desse formato em seu relatório da competência de 2009, para demonstrar o volume de exportações para cada bloco econômico relacionado, conforme se pode verificar no Gráfico 4.

\section{Gráfico 4 - Gráficos de Setores em Rosca}
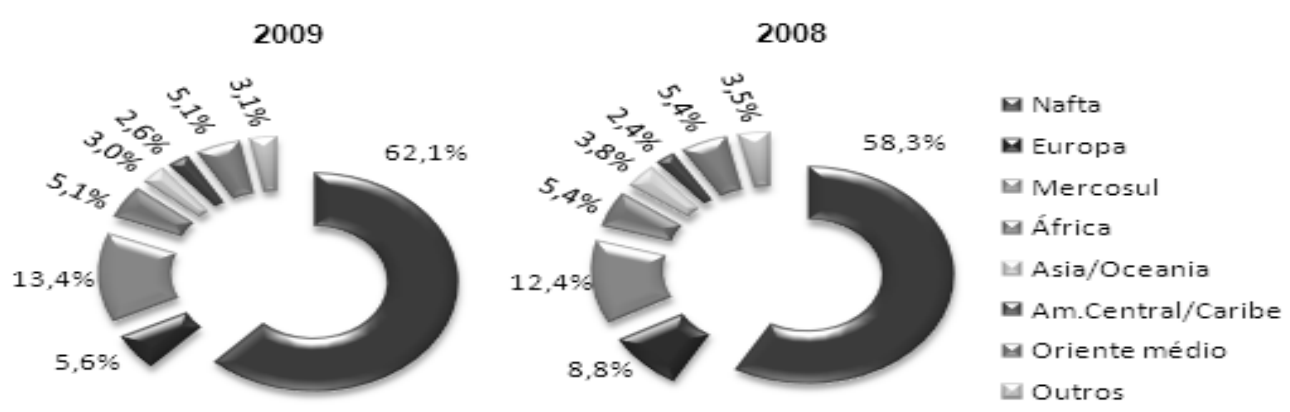

Fonte: Relatório Anual Corporativo - Fras-Le S.A. (2009, p. 10)

Os diagramas de barra apesar de seguirem o mesmo princípio dos gráficos de colunas, isto é, a comparação de diferentes quantidades entre duas variáveis, foram pouco utilizados, alcançando apenas 0,99\% do total. Das 19 empresas que optaram por esse tipo de visualização de dados a que se destacou foi a Light Serviços de Eletricidade S.A., com um total de 5 gráficos de barras, uma parcela de 12,2\% dos 41 gráficos apresentados. Esse formato foi utilizado principalmente para ilustrar variações de índices em um determinado espaço de tempo, como se pode verificar no Gráfico 5, que demonstra a evolução do Fluxo de Caixa da Souza Cruz S.A. em 2009.

Gráfico 5 - Gráfico de Barras

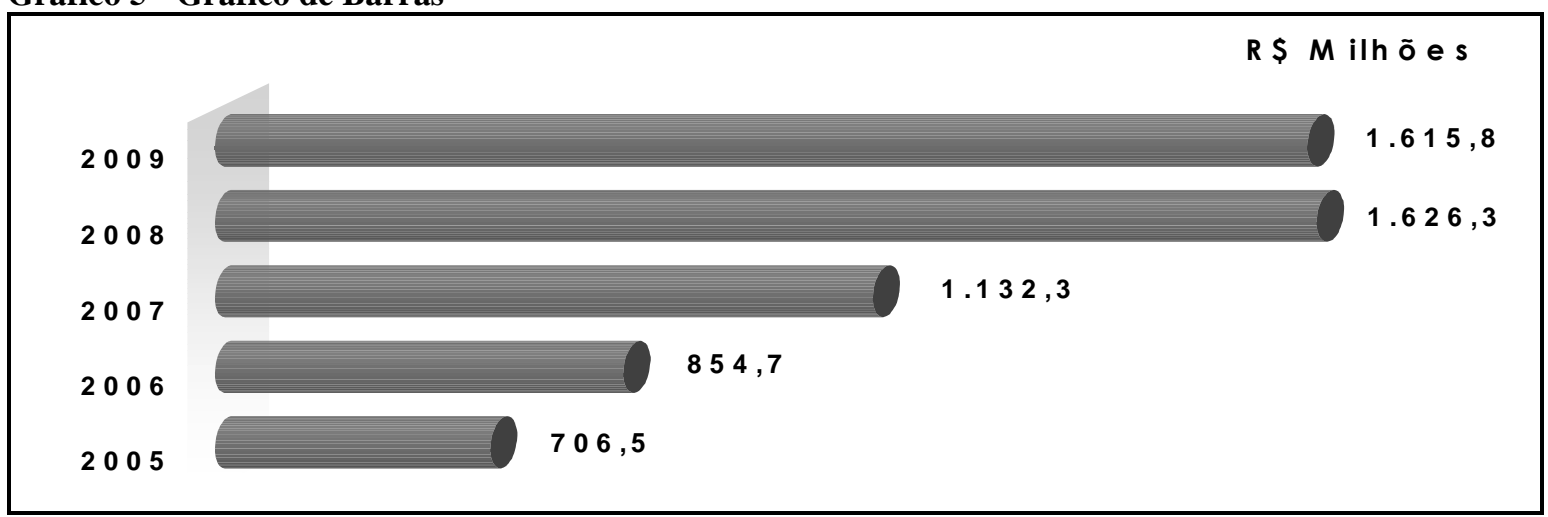

Fonte: Relatório Anual Corporativo - Souza Cruz S.A. (2009, p. 8)

Finalmente, os gráficos de área foram aqueles com a menor taxa de utilização, sendo ela $0,29 \%$ dos 4.127 gráficos analisados. Somente 7 empresas representaram seus dados dessa maneira e todas apresentaram somente um gráfico de área por relatório. A Mundial S.A Produtos de Consumo, atuante em vários setores industriais, demonstrou a taxa de produtividade de seus funcionários em seus relatórios referentes aos anos de 2004 a 2009 com 
um gráfico de área (Gráfico 6), sempre destacando essa taxa nos últimos 4 anos.

Gráfico 6 - Gráfico de Área

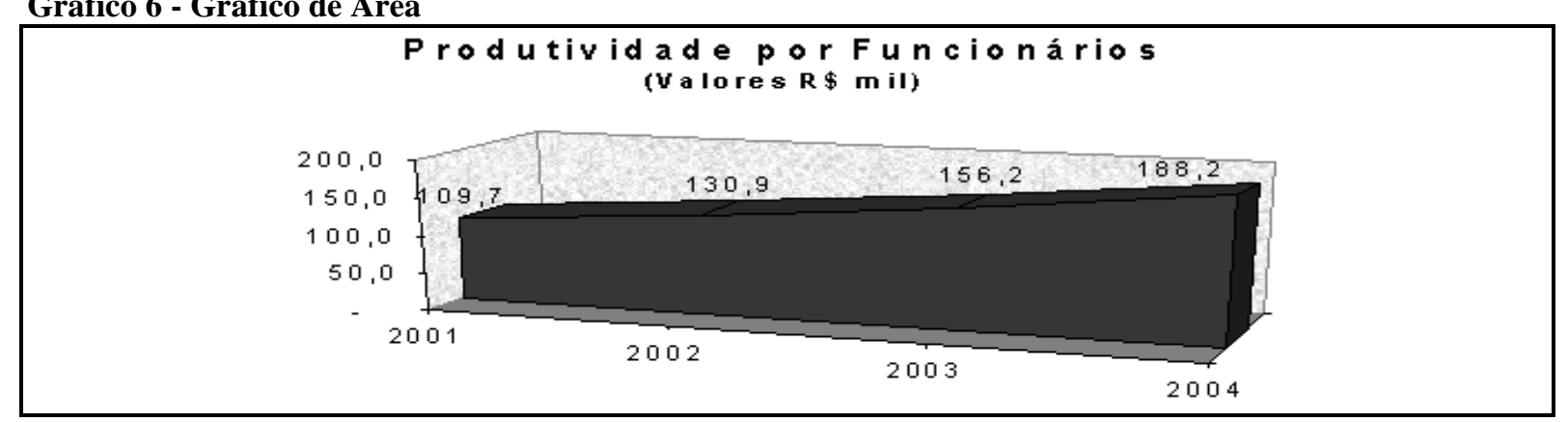

Fonte: Relatório Anual Corporativo - Mundial S.A. (2009, p. 8)

\subsection{Formas de Risco}

Por fim, avaliou-se o gerenciamento da apresentação gráfica partindo das formas de risco relacionadas: a utilização de base maior que zero e o emprego da perspectiva em 3 dimensões.. Considerando-se que esses dois índices, segundo Beattie e Jones (1992), podem ocasionar interpretações deturpadas dos dados, foi observado um total de 1.689 gráficos que apresentam pelo menos um desses índices. Essa soma variou de 54 gráficos em 1998, representando 3,37\% até 223 gráficos em 2009, ou 13,2\% do total. A evolução constante no Gráfico 7 ilustra a existência de variação relevante de gráficos que apresentaram formas de risco.

Gráfico 7 - Quantidade de Gráficos com Realce de Apresentação

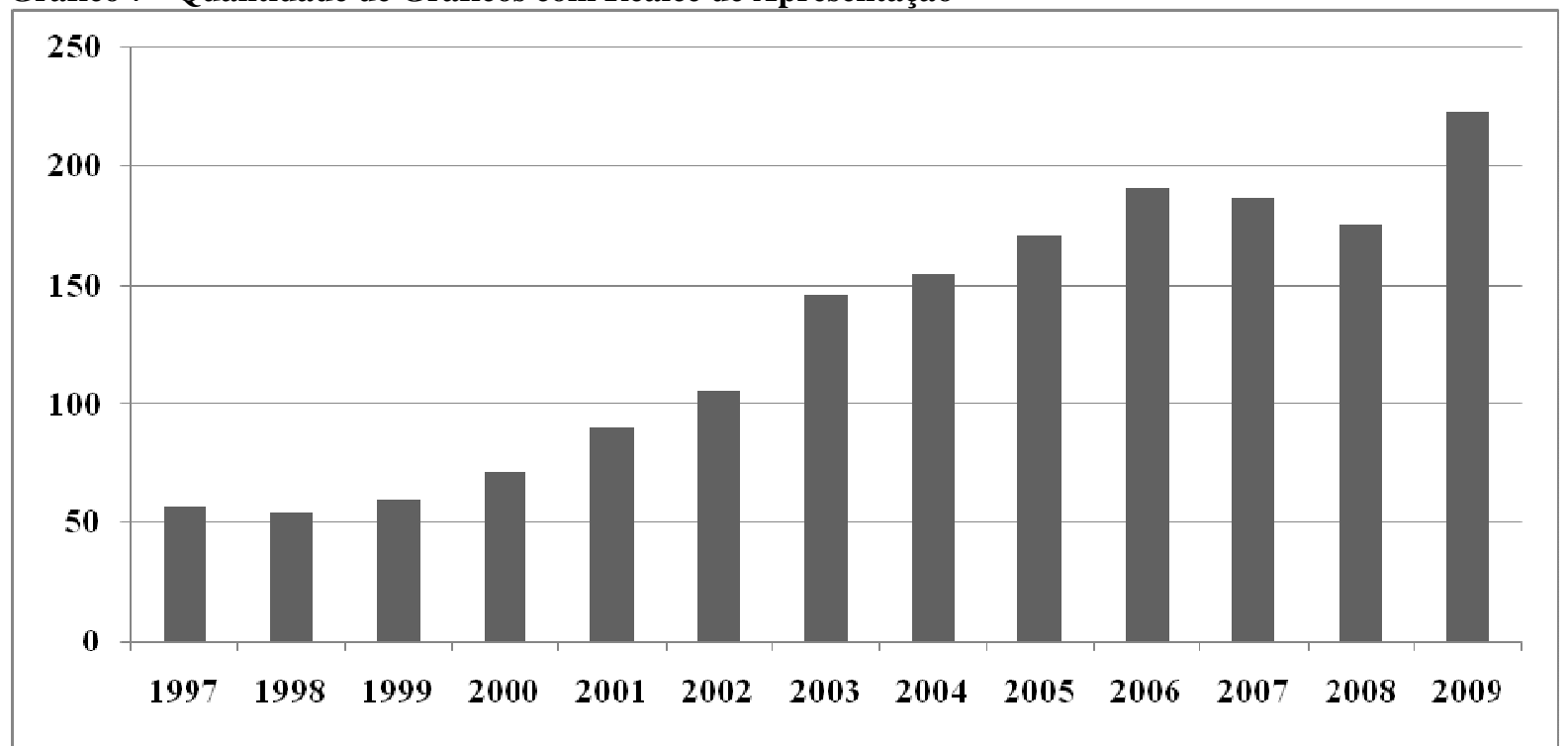

Fonte: Elaboração Própria

Das empresas analisadas, 80 delas apresentaram pelo menos um gráfico em 3D ou com a base diferente de zero. Significa que 39,41\% das empresas apresentaram diagramas tecnicamente corretos, mas que podem dar margem a conclusões erradas. Considerando somente essas entidades, a média de gráficos com efeitos de distorção foi de 1,62 por relatório.

Observou-se ainda, no decorrer da análise, que algumas empresas apresentaram esses dois índices em um mesmo gráfico, como o exemplo extraído do RA de 2005 da Mangels S.A. (Gráfico 8), que apresenta a evolução da Receita Bruta da empresa. 
Gráfico 8 - Gráfico com Base não-zero e 3D

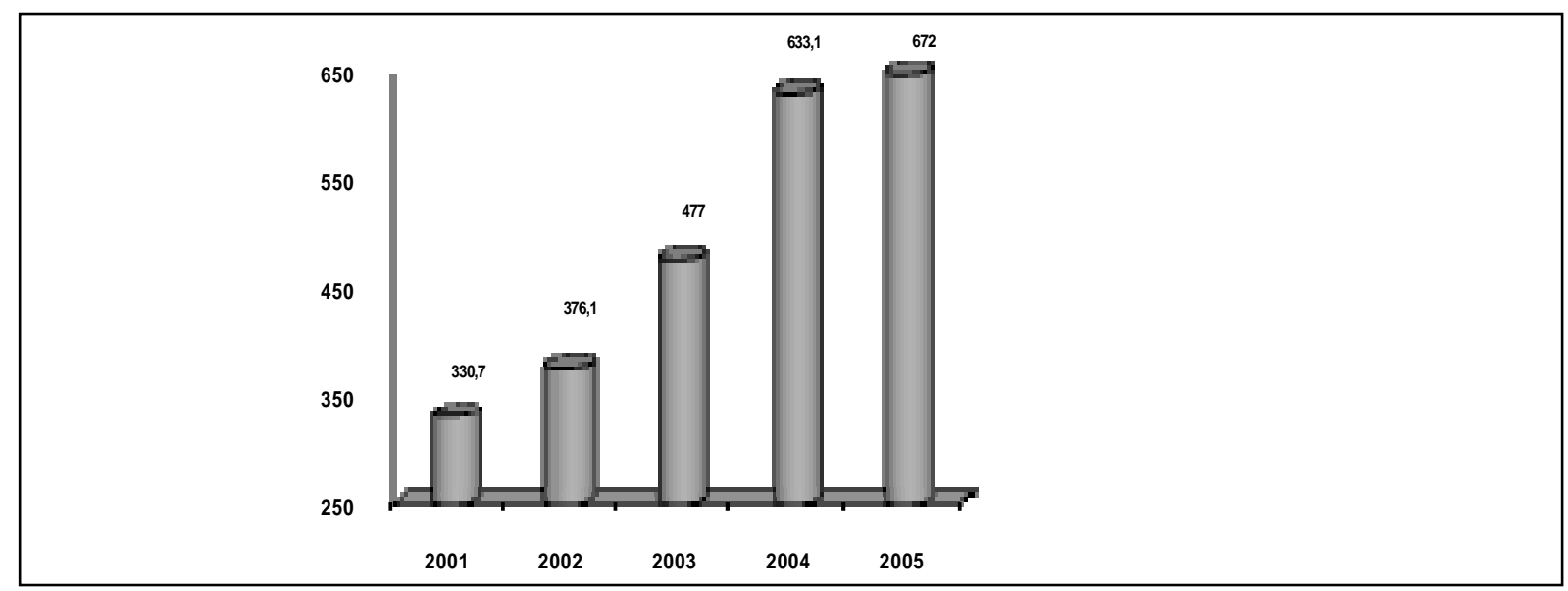

Fonte: Relatório Anual Corporativo - Mangels S.A. (2005, p. 2)

Com isso, na Tabela 3, que apresenta a classificação dos gráficos nesses índices ao longo do período analisado, a coluna "ambos" são os gráficos observados que apresentaram os dois realces de apresentação. O total de gráficos apresentados com forma de risco representou 40,93\% do total de 4.127 gráficos analisados. Essa taxa alcançou o pico em 1998 e 2007 foi o ano com o menor índice de gráficos com a base maior que zero e/ou em 3D.

Tabela 3 - Gráficos com Realce de Apresentação

\begin{tabular}{c|c|c|c|c|c|c}
\hline ANO & BASE $>0$ & 3 D & AMBOS & TOTAL & $\begin{array}{c}\text { TOTAL NO } \\
\text { ANO }\end{array}$ & $\%$ \\
\hline 1997 & 1 & 53 & 3 & 57 & 87 & $65,52 \%$ \\
1998 & 0 & 50 & 4 & 54 & 70 & $77,14 \%$ \\
1999 & 8 & 49 & 3 & 60 & 126 & $47,62 \%$ \\
2000 & 18 & 51 & 3 & 72 & 131 & $54,96 \%$ \\
2001 & 17 & 69 & 5 & 91 & 178 & $51,12 \%$ \\
2002 & 16 & 88 & 2 & 106 & 224 & $47,32 \%$ \\
2003 & 21 & 123 & 2 & 146 & 288 & $50,69 \%$ \\
2004 & 20 & 129 & 6 & 155 & 412 & $37,62 \%$ \\
2005 & 14 & 145 & 12 & 171 & 462 & $37,01 \%$ \\
2006 & 18 & 172 & 1 & 191 & 462 & $41,34 \%$ \\
2007 & 21 & 164 & 2 & 187 & 544 & $34,38 \%$ \\
2008 & 9 & 161 & 6 & 176 & 504 & $34,92 \%$ \\
2009 & 11 & 209 & 3 & 223 & 639 & $34,90 \%$ \\
\hline TOTAL & 174 & 1.463 & 52 & 1.689 & 4.127 & $40,93 \%$ \\
\hline
\end{tabular}

Fonte: Elaboração Própria

Mesmo sendo o índice utilizado com menor frequência, 43 empresas apresentaram gráficos com a origem maior que zero, alcançando o pico de utilização nos anos de 2003 e 2007 com 12,07\% do total de 174. A empresa que mais utilizou dessa técnica, foi a Eletrobrás, totalizando 17 gráficos ao todo, sendo 8 deles constantes no relatório de 2007. As outras duas empresas que alcançaram os maiores índices de utilização foram a Ampla Energia e Serviços S.A., com 16 gráficos e a Cesp - Companhia Energética de São Paulo, com 12 gráficos que possuem a base não-zero.

Ao longo de todo o período analisado, o emprego da perspectiva em 3 dimensões foi o realce mais utilizado. O menor índice de utilização foi em 2000, de 70,83\% dos 72 diagramas 
com alguma forma de risco observada. Por outro lado, em 2009 esse índice alcançou 93,72\%. Apesar da Vulcabras S.A. ter apresentado todos os 75 gráficos em 3D no relatório de 2009, a empresa que totalizou a maior quantidade desses diagramas foi a Braskem S.A. com 119, seguida pela própria Vulcabras com 104 e a Randon S.A. Implementos E Participações, com 62. Foi observado o uso dessa perspectiva em todos os tipos de gráfico, com exceção dos cartesianos. Quanto aos gráficos que apresentaram os dois índices ao mesmo tempo, a empresa que totalizou a maior quantidade (7 gráficos) em todos os 13 anos, foi o Banestes S.A. - Banco do Estado do Espirito Santo.

Um ponto relevante nessa análise foi o fato de 7 empresas apresentarem todos os seus gráficos com pelo menos uma dessas formas de realce de apresentação. Essas entidades estão correlacionadas na Tabela 4, seguidas da quantidade total de gráficos utilizados e suas respectivas características.

Tabela 4 - Empresas com 100\% dos Gráficos com Realce de Apresentação

\begin{tabular}{|c|c|c|c|c|c|c|}
\hline \multirow{2}{*}{ EMPRESA } & \multicolumn{2}{|c|}{ TOTAL } & \multicolumn{2}{|c|}{ FORMATO } & \multicolumn{2}{|c|}{ FORMA DE RISCO } \\
\hline & QTDD & $\mathrm{ANO}$ & QTDD & TIPO & QTDD & ÍNDICE \\
\hline \multirow{3}{*}{ Banco do Estado do Pará S/A. } & 6 & 200 Q & 6 & COU UNAS & 2 & $3 \mathrm{D}$ \\
\hline & U & & 0 & & 4 & AMBOS \\
\hline & 5 & 2009 & 5 & COLUNAS & 5 & $3 \mathrm{D}$ \\
\hline \multirow{3}{*}{ Bardella S.A. Inds Mecânicas } & 2 & 2007 & 2 & PIZZA & 2 & $3 \mathrm{D}$ \\
\hline & 2 & 2008 & 2 & PIZZA & 2 & $3 \mathrm{D}$ \\
\hline & 2 & 2009 & 2 & PIZZA & 2 & $3 \mathrm{D}$ \\
\hline \multirow{3}{*}{ Bombril S.A. } & 1 & 1999 & 1 & BARRAS & 1 & $3 \mathrm{D}$ \\
\hline & 2 & 2003 & 2 & COLUNAS & 2 & $3 \mathrm{D}$ \\
\hline & 2 & 2005 & 2 & COLUNAS & 2 & $3 \mathrm{D}$ \\
\hline \multirow{6}{*}{$\begin{array}{l}\text { Cia Estadual de Geração e } \\
\text { Transmissão de Energia } \\
\text { Elétrica }\end{array}$} & 2 & 1998 & 2 & PIZZA & 2 & $3 \mathrm{D}$ \\
\hline & 3 & 2000 & 3 & PIZZA & 3 & $3 \mathrm{D}$ \\
\hline & 1 & 2002 & 1 & PIZZA & 1 & $3 \mathrm{D}$ \\
\hline & 1 & 2003 & 1 & PIZZA & 1 & $3 \mathrm{D}$ \\
\hline & 1 & 2004 & 1 & PIZZA & 1 & $3 \mathrm{D}$ \\
\hline & 1 & 2005 & 1 & PIZZA & 1 & $3 \mathrm{D}$ \\
\hline \multirow{3}{*}{ Dixie Toga S.A. } & 6 & 2002 & 6 & COLUNAS & 6 & $3 \mathrm{D}$ \\
\hline & 5 & 2003 & 5 & COLUNAS & 5 & $3 \mathrm{D}$ \\
\hline & 5 & 2004 & 5 & COLUNAS & 5 & $3 \mathrm{D}$ \\
\hline \multirow{2}{*}{ Hopi Hari S.A. } & \multirow{2}{*}{4} & \multirow{2}{*}{2004} & \multirow{2}{*}{4} & \multirow{2}{*}{ COLUNAS } & 2 & AMBOS \\
\hline & & & & & 2 & $3 \mathrm{D}$ \\
\hline Marisol S.A. & 1 & 2007 & 1 & PIZZA & 1 & $3 \mathrm{D}$ \\
\hline
\end{tabular}

Fonte: Elaboração Própria

\section{CONCLUSÕES}

O objetivo desse estudo é analisar os recursos visuais apresentados nos RA, buscandose analisar a quantidade, os tipos e características desses elementos visuais, bem como se há indicadores de realce de apresentação nos gráficos apresentados nesses relatórios.

Verifica-se uma utilização maior dos diagramas, em vista da praticidade que essas ferramentas representam na comunicação empresarial. O recurso visual de maior utilização foram as tabelas, principalmente por serem capazes de demonstrar o valor exato de uma categoria, o que pode não acontecer com as variáveis em um gráfico, e torna-se um importante fator quando estão sendo relacionados valores em dinheiro, principalmente. 
O formato de gráfico mais utilizado foi o composto por colunas, justificado pelo fato de que, para comparar valores, as retas são eficazes, pois, como destacado por Wurman (1991): "se você tem uma reta, pode ver facilmente se ela é o dobro da outra". Por outro lado, muitas vezes os elaboradores dos RAs não se dão conta de que gráficos de setores, ou até mesmo os de área, costumam ser as melhores opções para exibir a relação de diferentes categorias com o todo.

Entretanto, dado o volume expressivo de gráficos que não seguem os padrões de conformidade de sua construção, cabe a quem utiliza do relatório corporativo na tomada de decisão distinguir a veracidade das informações ali "desenhadas". Huff (1954, p. 67) alerta: "desconfie de qualquer versão em que as barras mudam tanto de altura como de largura [...], ou quando aparecem objetos de três dimensões cujos volumes não sejam facilmente comparáveis". Logo, é preciso discernimento daquele que vai elaborar o relatório utilizando gráficos, para elucidar o usuário e não apenas impressionar.

Como sugerido por Beattie e Jones (1992), constatado o nível elevado de uso de gráficos que apresentam formas de risco e a neutralidade das informações apresentadas poder estar prejudicada por meio dessas manipulações visuais, é necessário orientações explícitas para essa abordagem contábil. Uma auditoria específica é de fundamental importância, para desenvolver diretrizes tanto para quem elabora, quanto para quem utiliza, julgar se os gráficos estão retratando a informação financeira de maneira imparcial.

Recomenda-se, para futuras pesquisas, incluir outros indicadores de distorção, como a utilização seletiva de cores ou a relação das variáveis apresentadas nos gráficos com o seu respectivo formato, bem como o impacto nas conclusões que podem ser inferidas desses diagramas.

\section{REFERENCIAS}

BEATTIE, V.; JONES, M. J. The Use and Abuse of Graphs in Annual Reports: Theoretical Framework and Empirical Study. Accounting and Business Research. v. 22, n. 88, p. 291303, 1992. http://dx.doi.org/10.1080/00014788.1992.9729446

BEATTIE, V.; JONES, M. J. Measurement distortion of $\mathrm{g}$ raphs in Corporate Reports: an experimental study. Accounting, Auditing \& Accountability Journal. v. 15, n. 4, p 546-564, 002a. http://dx.doi.org/10.1108/09513570210440595

BEATTIE, V.; JONES, M. J. The Impact of Graph Slope on Rate of Change Judgments in Corporate Reports. Abacus. v. 38, n. 2, 2002b. http://dx.doi.org/10.1111/1467-6281.00104

BEDFORD, N. M.; BALADOUNI, V. A communication theory approach to accounting. Accounting Review, v.12, p. 650-659, 1962.

BRASIL. Lei no 6.404, de 15 de dezembro de 1976. Dispõe sobre as sociedades por ações. Diário Oficial República Federativa do Brasil, Brasília, DF, 17 dez. 1976. Disponível em: <http://www.planalto.gov.br/ccivil_03/Leis/L6404consol.htm>. Acesso em: 13 mar. 2011.

CHO, C.; MICHELON, G.; PATTEN, D. Impression Management in sustainability reports. Working Paper. Disponível em: <http://gin.confex.com/gin/2010/>. Acesso em: 24 Ago 2011

CLATWORTHY, M.; JONES, M. J. The effect of thematic structure on the variability of annual report readability. Accounting, Auditing \& Accountability Journal. MCB University Press. v. 14, n. 3, p. 311-326, 2001. http://dx.doi.org/10.1108/09513570110399890

COMISSÃO DE VALORES MOBILIÁRIOS. Parecer de Orientação $\mathbf{n}^{\circ} \mathbf{1 5}$, de 28 de dezembro de 1987. Disponível em: 〈http://www.cvm.gov.br>. Acesso em: 13 mar. 2011. 
CUNHA, S. E. Estatística descritiva: na psicologia e na educação. Rio de Janeiro: Forense, 1982.

CUNHA, R. K. C.; SILVA, C. A. T. Análise da Facilidade de Leitura das Demonstrações Contábeis das Empresas Brasileiras: uma investigação do gerenciamento de impressões nas narrativas contábeis. In: Congresso USP de Controladoria e Contabilidade, 9., 2009. Anais... São Paulo: FEA/USP, 2009.

DALMÁCIO, F. Z.; PAULO, F. F. M. A evidenciação contábil: publicação de aspectos sócioambientais e econômico-financeiros nas demonstrações contábeis. In: Congresso USP de Controladoria e Contabilidade, 4., 2004. Anais... São Paulo: FEA/USP, 2004.

DIAS FILHO, J. M. A Linguagem Utilizada na Evidenciação Contábil: uma Análise de sua Compreensibilidade à Luz da Teoria da Comunicação. Caderno de Estudos FIPECAFI, n. 24, p. 38 - 49, jul/dez 2000. http://dx.doi.org/10.1590/S1413-92512000000200003

GALlON, A.V.; BEUREN, I. M. Análise de Conteúdo dos Itens Obrigatórios ou Recomendados e de Divulgação Espontânea no Relatório da Administração das Companhias Abertas. Revista de Educação e Pesquisa em Contabilidade, Brasília, v. 2, n. 1, p. 47-70, jan/abr. 2008.

HUFF, D. How to Lie with Statistics. New York: W. Norton, 1954.

ILUF , O. M. V.. Teoria da Comunicação e Teoria da Semiótica: sua incorporação ao processo de formação universitária do contador no Chile. In: Conferência Acadêmica Permanente de Pesquisa em Contabilidade, 21. Assembléia Anual, 2000. Anais... Talca, 2000. Disponível em: <http://www7.rio.rj.gov.br/cgm/comunicacao/textos/conhecimento /arquivos/2003/01.pdf>. Acesso em: 15 mar. 2012.

IUDÍCIBUS, S. de. Teoria da Contabilidade. 9. ed. São Paulo: Atlas, 2009.

JONES, M. J. The nature, use and impression management of graphs in social and environmental accounting. Accounting Forum. v. 35, p. 75-89, 2011. http://dx.doi.org/10.1016/j.accfor.2011.03.002

LI, F. Annual report readability, earnings and stock returns. Working paper, NBER, p. 1- 46, 2006.

LIMA, D. H. S. Efeito formulação e contabilidade: uma análise da influência da forma de apresentação de demonstrativos e relatórios contábeis sobre o processo decisório de usuários de informações contábeis. Dissertação (Mestrado em Ciências Contábeis) Universidade de Brasília, Programa Multiinstitucional e Inter- Regional de Pós- Graduação em Ciências Contábeis, Brasília, 2007.

LOPES, P. A. Probabilidades \& Estatística. Rio de Janeiro: Reichmann \& Affons Editores, 1999.

MATTOS, A. N. de. Informação é Prata, Compreensão é Ouro: Um guia para todos sobre como produzir e consumir informação na Era da Compreensão. Disponível em: $<$ http://www.archive.org/details/InformacaoEPrataCompreensoEOuro>. Acesso em 25 mai. 2011.

MIRANDA, L. C.; VIEIRA, A.S.; LAGIOIA, U.C.T.; VASCONCELLOS, M.T.C. Utilização de Gráficos em Demonstrações Contábeis. Revista de Educação e Pesquisa em Contabilidade. Vol. 2, n. 3, art. 2, p. 16-35, set/dez. 2008.

MONTEIRO, C. E. F. Interpretação de Gráficos: Atividade social e conteúdo de ensino. In: ANPED, 22. Reunião Anual, Caxambu, 1999. Anais... 1999. Disponível em 
<http://www.seed.pr.gov.br/portals/roteiropedagogico/publicacao/4357_Texto_Monteiro.pdf>. Acesso em 22/03/2011.

PEREIRA, C. C.; FRAGOSO, A. R.; RIBEIRO FILHO, J. F. Comunicação em contabilidade: um estudo comparativo do nível de percepção dos usuários da informação contábil em Florianópolis (SC) e Recife (PE) sobre a utilidade das representações gráficas no processo de evidenciação. In: Congresso USP de Controladoria e Contabilidade, 4., 2004. Anais... São Paulo: FEA/USP, 2004.

REIS, E. Estatística descritiva. 7 ed. Lisboa: Sílabo, 2008.

ROGERS, R. K.; GRANT, J. Content Analysis of Information Cited in Reports of Sell-Side Financial Analysts. Journal of Financial Statement Analysis, v. 3, n. 1, p.17-30, Outono, 1997.

SILVA, C.A.T.; RODRIGUES, F.F. Análise das Variáveis que Influenciam as Informações Divulgadas nos Relatórios de Administração das Companhias Abertas Brasileiras: Um estudo empírico nos anos de 2001 a 2003. In: Congresso USP de Controladoria e Contabilidade, 6., 2006. Anais... São Paulo: FEA/USP, 2006.

SILVA C.A.T; RODRIGUES, M. G. A relevância do relatório da administração para o usuário da informação: um estudo experimental. RIC - Revista de Informação Contábil, v. 4, n. 1, p. 41-56, Jan-Mar/2010.

SPRINGER, L. Enhancing the Annual Report: Investor Relations and the MD\&A. The Journal of Bank Accounting \& Auditing, v. 5, n. 2, p.27-29, 1992.

TUFTE, E. R. The Visual Display of Quantitative Information. Grafic Press. 2001.

SYDSERFF, R.; WEETMAN, P. Developments in Content Analysis: a transitivity índex and DICTION score. Accounting, Auditing \& Accountability Journal, v. 15, n. 4, p. 523-545, 2002. http://dx.doi.org/10.1108/09513570210440586

TESSAROLO, I. F.; PAGLIARUSSI, M. S.; LUZ, A. T. M. The Justification of Organizational Performance in Annual Report Narratives. Brazilian Administration Review (BAR), v. 7, n. 2, p. 198-212, Apr-Jun, 2010. http://dx.doi.org/10.1590/S180776922010000200006

VICENTE, E. F. R.; ALVES, J. L.; BORBA, J. A.; SCHARF, L. Aderência do relatório da administração das Empresas listadas no novo mercado da bovespa ao Guia de boas práticas de governança corporativa da UNCTAD. Revista de Contabilidade do Mestrado em Ciências Contábeis da UERJ, Rio de Janeiro, v. 12, n. 2, p. 1, maio/ago, 2007.

WURMAN, R.S. Ansiedade de informação; como transformar informação em compreensão. 2 ed. São Paulo: Cultura, 1991.

YUTHAS, K.; ROGERS, R.; DILLARD, J. F. Communicative Action and Corporate Annual Reports. Journal of Business Ethics, v. 41, p. 141, 2002. http://dx.doi.org/10.1023/A:1021314626311 